\title{
Elementos para uma análise marxista da instabilidade política no Estado burguês*
}

Aldo Durán Gil**

\section{INTRODUÇ̃̃o}

Neste trabalho propomos uma análise marxista sobre a problemática da instabilidade política no quadro do funcionamento reprodutivo do Estado burguês, dando especial ênfase ao fenômeno nos Estados da periferia do capitalismo. Partimos do suposto teórico de que as diversas modalidades de instabilidade política estão sobredeterminadas pelas crises políticas. O que nos leva a definir o que entendemos por crise política e instabilidade política e refletir teoricamente a sua relação no âmbito do Estado burguês. Logo buscamos compreender como determinadas crises políticas se traduzem em fontes ou modalidades importantes de instabilidade política no tipo de Estado burguês de exceção: o Estado militar.

\section{CRISE POlítica e INSTABILIDADE POlítica No Estado bURGUÊS}

O tratamento analítico do fenômeno da instabilidade política supõe uma prévia reflexão teórica sobre a sua construção como objeto de estudo e sobre o lugar que ocuparia, de acordo com a opção teórica aqui adotada, na teoria marxista regional do

\footnotetext{
* Versão ligeiramente corrigida de um item do primeiro capítulo da minha tese de doutorado “Estado militar e instabilidade política na Bolívia (1971-1978)", defendida em 2003 no IFCH/Unicamp.

**Doutor em Ciências Sociais, professor Adjundo da Universidade Federal de Uberlândia (UFU).
} 
político ${ }^{1}$. As causas fundamentais da instabilidade política devem ser identificadas em dois níveis importantes: 1) no funcionamento da economia no modo de produção capitalista (estrutura econômica), o qual tem um caráter contraditório e instável e que provoca efeitos no âmbito do aparelho de Estado; 2) no funcionamento do Estado (estrutura jurídico-política), o qual também tem um caráter contraditório e gerador potencial de instabilidade político-institucional.

Em relação ao nível da estrutura econômica, sabemos, principalmente pelas análises de Marx em $O$ Capital $^{2}$, que a lógica de funcionamento desse sistema é caracterizada por sua natureza contraditória e instável, provocadas tanto pela anarquia da produção capitalista como pelas crises periódicas nos planos da produção, distribuição e circulação3. Um aspecto importante da contradição é detectado no próprio processo de acumulação: este é determinado pela apropriação do trabalho do produtor direto pelo proprietário dos meios de produção - isto é, a mais-valia extraída do trabalhador assalariado é açambarcada pela classe capitalista exploradora, instaurando-se assim, no próprio processo de produção a tendência da luta entre trabalho versus capital. $\mathrm{Na}$ fase da reprodução ampliada (passagem da extração de mais-valia absoluta à relativa), emerge uma outra contradição fundamental: a baixa tendencial da taxa média de lucro. Os diversos momentos da produção capitalista (circulação, distribuição, consumo) na suas fases de reprodução simples e ampliada são reproduzidos com essa contradição inerente ao processo de acumulação. Por outro lado, essa lógica de funcionamento da economia capitalista é atravessada por uma tendência permanente de crises gerais (ondas longas, com caráter mais desestabilizador do sistema capitalista) e de ciclos e flutuações econômicas de prosperidade e declínio, que provocam crises econômicas potenciais a curto e médio prazos. Trata-se de dois tipos de crise geral: a crise estrutural e a crise conjuntural. No entanto, detecta-se também uma contra-tendência: a neutralização das crises gerais e o amortecimento das crises de curto e médio prazos. Esse

1. Essa teoria foi elaborada por Poulantzas em Poder Político e Classes Sociais (2ª ed. São Paulo, Martins Fontes, 1986) em 1968, cujo conceito central é o conceito de Estado capitalista.

2. Crises periódicas de curto e médio prazos - com uma duração média de 10 anos - marcadas por várias fases: desenvolvimento do capital fixo (expansão), depressão, atividade média, precipitações e crises. Tais crises tendem a provocar crises de longo prazo (crises estruturais), as quais estão relacionadas com a intensificação de uma crise particular (que emerge do próprio processo de produção capitalista): a baixa tendencial da taxa média de lucro. Consultar O Capital, principalmente o volume II.

3. É impossível aqui abordar o caráter das diversas crises econômicas desde Marx, Lênin, passando por Hilferding, Luxemburgo, Gramsci, Kondratief, Kalecki e Mandel.

88 Elementos para uma análise marxista da instabilidade política no Estado burguês 
movimento contraditório do sistema capitalista está eivado de crises que se convertem em fontes potenciais de instabilidade econômica que repercutem incisivamente em instabilidade no plano político. No estágio do capitalismo monopolista de Estado, tais ciclos e flutuações são agravados pela baixa tendencial da taxa média de lucro: um índice importante de instabilidade crescente do sistema capitalista. Em suma, a instabilidade do funcionamento do sistema capitalista, que tem um caráter invariante (nos dois sentidos: a tendência/contra-tendência de reprodução e neutralização das crises) decorre do efeito das contradições tanto no nível da produção e das relações de produção como no nível da reprodução ampliada do capital.

No âmbito da estrutura jurídico-política (Estado), os prin cipais fatores invariantes causadores de instabilidade política potencial estão relacionados aos efeitos produzidos pelo desempenho das funções fundamentais do Estado burguês ${ }^{4}$. Em primeiro lugar, esse Estado desempenha uma "função-limite" de frustrar, através do exercício da força, "a revolução social anticapitalista". Tal função-limite "é desempenhada pelos Estados capitalistas de um modo regular e contínuo, e não apenas em situações revolucionárias; a força, quando deixa de ser aplicada por tais Estados, é pelo menos ostentada e exibida, produzindo desse modo efeitos intimidatórios sobre as forças potencialmente revolucionárias" 5 . Pode-se deduzir que o desempenho dessa função é um indicador relevante (mas não o único) do empenho desse Estado na busca de regularidade e

4. Deve-se esclarecer que o fenômeno da instabilidade política não é exclusivo do Estado burguês. Partimos do suposto de que tal fenômeno é constitutivo do Estado em geral. Ao analisar o sistema de dominação política nas formações sociais coloniais na América (séculos XVI em diante), Caravaglia (In: Carlos Sempat Assadourian et al., Modos de producción en América Latina. 2ª ed. Buenos Aires, Pasado y Presente, 1974, p. 14-15) detecta um sistema político amplamente movediço, conferindo um caráter politicamente instável ao funcionamento do Estado nessa formação social: poder político composto pela aliança entre um aparato burocrático (representante do Estado metropolitano) e as diversas frações das classes proprietárias da colônia. Saes (A formação do Estado burguês no Brasil (1888-1891). 2ª ed. Rio de Janeiro, Paz e Terra, 1990, p. 94-95) vai mais longe ao utilizar o conceito de bloco no poder formulado por Poulantzas, que restringe o uso exclusivo de tal conceito ao Estado burguês, na análise da formação social escravista brasileira do período colonial. E detecta uma instabilidade hegemônica (conceito poulantziano também criativamente utilizado por Saes) no seio do bloco no poder no Estado escravista colonial: "era hegemônico o sub-bloco que obtinha, a cada momento, maiores vantagens no comércio colonial: ora as classes dominantes locais, ora as classes dominantes metropolitanas. Ao longo do período colonial, registram-se inúmeras redefinições da hegemonia [...]" (Idem, ibidem, p. 95). E conclui: “Essa instabilidade hegemônica perdurou até a definição, em caráter permanente, de uma nova situação [...]" (idem.).

5. Décio Saes, República do capital - capitalismo e processo político no Brasil. São Paulo, Boitempo, 2001, p. 49; grifo nosso.

Economia e sociedade no capitalismo contemporâneo

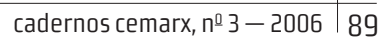


estabilidade na formação social, nas esferas econômica (garantir o funcionamento e reprodução do sistema capitalista) e política (garantir o funcionamento e reprodução da estrutura jurídico-política). Logo, o empenho na busca de estabilidade pelo Estado burguês não é exclusivo da sua função-limite, conforme veremos a seguir, pois tal função não é a única a ser desempenhada por esse tipo de Estado.

Mais especificamente, os fatores potenciais de instabilidade política estão relacionados com a dupla função essencial do Estado burguês, constitutiva do conceito desse tipo particular de Estado: 1) a individualização dos agentes da produção ou a sua conversão em sujeitos de direito; e 2) a neutralização da tendência do trabalhador assalariado (produtor direto) a se organizar em classe social para se contrapor ao proprietário dos meios de produção (note-se a importância que exerce o direito burguês na esfera da produção na medida em que confere uma regularidade e previsibilidade do comportamento dos agentes econômicos). Em relação ao produtor direto, através da segunda função, o Estado dissolve a classe social e impõe uma representação coletiva de caráter superclassista: o Povo-Nação. ${ }^{6}$

No nível da estrutura jurídico-política, esse tipo de representação - que também pode ser denominada representação burocrática - é invariavelmente exercida pela burocracia estatal sob o comando do burocratismo. Numa formação social capitalista concreta, ela entra em contradição com as formas de representação propriamente política (formas de dominação burguesa como, por exemplo, a democracia política), cuja solução, em geral, tende à liquidação desta. A natureza autoritária do burocratismo burguês e a intervenção da burocracia provocam instabilidade política potencial

6. Cf. Décio Saes. Estado e democracia: ensaios teóricos. Campinas, IFCH/Unicamp, 1994, p. 29-32. Preferimos utilizar o duplo efeito (de isolamento e de representação da unidade no Povo-Nação) formulado por Poulantzas nos termos colocados por Saes, quem critica o caráter genérico, portanto problemático, do segundo efeito no esquema poulantziana: ele nada agregaria diante o primeiro efeito. Daía qualificação da função neutralizadora da representação da unidade como a dissolução da classe social, através da constituição do Povo-Nação. Essa última crítica a Poulantzas, aprofundada nesse trabalho através da inclusão de alguns aspectos essenciais do papel do direito burguês e do burocratismo, não abordados por este autor, é confirmada num outro artigo de Saes, para quem o elo mais fraco do sistema de quatro conceitos fundamentais do trabalho teórico de Poulantzas seria o conceito de representação da unidade: "Poulantzas não se empenhou em demonstrar teoricamente - embora tivesse os instrumentos para fazê-lo - que só uma burocracia estatal socialmente aberta e apoiada no princípio da competência pode inculcar nos agentes da produção um sentimento nacional, de caráter superclassista" (Saes, "A questão da autonomia relativa do Estado em Poulantzas", Crítica Marxista, São Paulo, Xamã, no 7, 1998, p. 51, nota 4).

90 Elementos para uma análise marxista da instabilidade política no Estado burguês 
na medida em que viabiliza a instauração constante de formas de Estado de exceção (fascismo, ditadura militar) constitutivas do Estado burguês e a tendência ao autoritarismo estatal nas formas democráticas que assume esse Estado.

Em segundo lugar, existe um outro conjunto de funções fundamentais do Estado burguês, não exclusivo desse tipo de Estado, que tem um caráter conflituoso e contraditório (porém não-antagônico, salvo numa situação de crise revolucionária no segundo tipo de função) e que produz fontes genéricas potenciais de crises e instabilidade política: 1) a unificação política das diversas classes ou frações de classe capitalista num bloco no poder e, por conseguinte a organização da hegemonia política sob a égide de uma classe ou fração de classe dominante; 2) a desorganização/reorganização das classes dominadas (desorganização da classe operária e representação política das classes da pequena produção - pequena burguesia, campesinato); 3) a elaboração da política de Estado - feita pela burocracia em conjunto com as classes dominantes que compõem o bloco no poder - em consonância com os interesses econômicos restritos da classe ou fração hegemônica.

Deve-se sublinhar que uma das causas fundamentais que determina as expressões invariantes de instabilidade no nível político - essa é a nossa hipótese - seria a incapacidade de qualquer classe ou fração de classe capitalista conquistar a hegemonia política (no conjunto da classe dominante e no conjunto da sociedade) sem a ação do Estado. Daí a importância do papel do Estado de organizar a hegemonia política. Embora não exista em Marx uma teoria sobre a problemática aqui enunciada, é possível encontrar argumentos em "estado prático" sobre a relação entre crise e estabilidade/instabilidade política. Nas suas obras históricas, e mais propriamente políticas, Marx mostra claramente pelo menos duas importantes características inerentes à prática das classes dominantes na formação social capitalista que geram diversos tipos de crise política: 1) a luta entre as diversas frações de classe (junto com seus representantes políticos) e sua constante fragmentação devido à concretização de seus interesses econômicos imediatos ou à corrida pela maximização dos lucros; 2) a dependência do aparelho de Estado para organizar a hegemonia política.

Em suma, a incapacidade das classes dominantes e frações de classe dominante de conquistar a hegemonia política sem a ação do Estado provém, de um lado, do profundo fracionamento característico, que começa no nível das relações de produção, da classe capitalista em frações antagônicas de classe; e de outro, da luta da classe ou fração hegemônica (e por extensão, do bloco no poder) contra as classes dominadas, da dificuldade de realizar sua hegemonia política em relação a estas. No nível da

Economia e sociedade no capitalismo contemporâneo

cadernos cemarx, n-3-2006 91 
dominação política, elas não apenas vivem atravessadas por lutas e fricções internas, mas também "afundadas em contradições que as tornam incapazes de governar politicamente". Assim, a confluência de contradições (a principal e as secundárias) origina, dado o seu funcionamento de classe, uma situação sempre instável da dominação no nível político. ${ }^{7}$ Ela também origina crises políticas constantes, dentre as quais as mais importantes estão: a crise de hegemonia, a crise de Estado, crise de organização e de representação partidária, crise ideológica, e no limite, a crise revolucionária.

Por outro lado, podemos mencionar outros dois fatores relevantes que se convertem em fontes importantes de instabilidade política no quadro de funcionamento do Estado burguês evocados por Saes: 1 ) o golpe de Estado (intervenção civil/militar), um dos fatores potenciais que produz instabilidade na esfera política; 2) a movimentação (ou mobilização) política das classes dominadas, que se constitui como o fator principal de instabilidade desse tipo de Estado. Podemos acrescentar que nas formas de Estado democrático e de regime democrático emergem tipos de instabilidade decorrentes de um elenco de fatores oriundos de crises do sistema político-partidário, dos conflitos entre a burocracia e o bloco no poder, dos sistemas de governo etc. (Executivo versus Parlamento, com dominância, no sistema presidencialista, do primeiro), que redundam em modalidades de instabilidade política governamental. Na atual fase do processo político na América Latina, o segundo tipo de instabilidade aparece reforçado pela ação das massas trabalhadoras em resistência à limitação das dimensões de cidadania, já conquistadas por estas numa fase anterior (certos direitos políticos e sociais), pelas classes dominantes; ou então, contra um vasto programa neoliberal (desmantelamento do "Estado intervencionista" que aparece como um combate redistributivo de renda "a favor das massas populares") encetado pelas classes dominantes e pela burocracia de Estado. Já numa forma de Estado autoritário e regime ditatorial-militar (que vigorou a partir de meados dos anos 60), a resistência das massas contra esse Estado potencializa a instabilidade política, na medida em que aquele é incapaz de desmobilizar politicamente, parcial ou completamente, o movimento operário e popular. Nesse sentido, pode-se denominar o Estado militar como um Estado constitutivamente instável.

Visto isso, surge agora o problema de compreender o sentido da variação do fenô-

7. Essa linha de análise é seguida por Engels, Lênin, Gramsci e Poulantzas (Cf. Poder político e classes sociais, cit., p. 294-95). 8. Estado e democracia, cit., p. 139-140.

92 Elementos para uma análise marxista da instabilidade política no Estado burguês 
meno da instabilidade política. O seu caráter variante estaria determinado, de um lado, pela relação do Estado com a luta de classes, e de outro, pelas modalidades ou tipos de crise política correspondentes a uma conjuntura específica de uma formação social capitalista concreta. Vale dizer, os limites de variação do fenômeno são fixados tanto pela intervenção do Estado através de suas funções como pelo papel que desempenha, aí, a luta de classes. Pode-se deduzir teoricamente que as diversas modalidades de crise política, como produto da relação entre o Estado e a luta de classe numa formação social capitalista concreta - isto é, no funcionamento desse tipo de sociedade -, circunscrevem ou delimitam (a variância) as modalidades de instabilidade política. Trata-se de uma variação dentro de uma invariância, carregada da seguinte contradição: o empenho do Estado em estabilizar as relações de classe (através do amortecimento do antagonismo de classe nos níveis das relações de produção e na estrutura jurídico-política; ou dito de outro modo, nos níveis do aparelho econômico e do aparelho estatal) que tendem a funcionar de forma instável. Assim, a relação complexa do Estado com a luta de classes produz uma tendência oscilatória inerente à reprodução do Estado burguês: a estabilidade/instabilidade política. A ruptura dos limites impostos por essa relação é a emergência da revolução social.

Em suma, através das suas principais funções, o Estado garante as condições ideológicas/políticas necessárias para a reprodução das relações de produção capitalista e organiza de um modo particular a dominação de classe: organização interna do aparelho de Estado comandada pelas regras do burocratismo. Estabiliza as relações sociais capitalistas com vistas a amortecer o antagonismo de classe (luta de classes) nos níveis das relações de produção e da estrutura jurídico-política. Ao estabilizar as relações sociais capitalistas (no nível econômico), constitutivamente contraditórias, o Estado cria as condições genéricas potenciais de instabilidade nos níveis político e ideológico. Segue-se disso que uma análise da instabilidade política deve tomar em conta os seus aspectos teóricos essenciais (invariância) para identificar as suas diversas modalidades (variância) determinadas pela relação do Estado e a luta de classes numa formação social concreta.

Das observações teóricas supramencionadas podemos extrair três proposições básicas que visam orientar a análise da nossa problemática:

1) Ao propiciar as condições necessárias para a reprodução das relações capitalistas de produção, o Estado burguês produz, através das suas funções essenciais, contradições e crises provocadas pela luta de classes nos níveis econômico, político e ideológico. Ou por outra, ao cumprir o papel de amortecer e estabilizar os conflitos

Economia e sociedade no capitalismo contemporâneo

cadernos cemarx, n-3-2006 93 
e antagonismos de classe (através de sua função-limite de frustrar a revolução anticapitalista), criando as condições ideológicas necessárias à reproduç̧̃ão das relações capitalistas de produção, o Estado burguês tende a se constituir como um Estado portador de crises e contradições em razão da luta de classes nos diversos níveis da estrutura social. Logo, ele tende também a se constituir como um Estado que é atravessado pela constante instabilidade política devido ao efeito dessas crises e contradições das relações de classe.

2) A instabilidade política no Estado burguês dependente tende a ser mais acentuada devido à intensidade das crises políticas e contradições das relações de classe na fase pela qual atravessam as formações sociais da periferia do capitalismo, como o caso dos países latino-americanos.

3) Conclui-se assim que não é possível analisar a instabilidade política sem referenciá-la às crises políticas que as originam no âmbito do funcionamento reprodutivo do Estado burguês: a primeira pressupõe teoricamente as segundas.

\section{ConCEITOS DE CRISE E INSTABILIDADE POlíticA}

Já temos elementos suficientes para definir os conceitos de crise politica e de instabilidade política. A crise política consiste essencialmente em uma série de características particulares do campo da luta de classes e que é entendida como uma situação de condensação das contradições inerentes à estrutura social ${ }^{9}$. O que significa

9 Adotamos o conceito marxista de crise política proposto por Poulantzas em Fascismo e Ditadura (São Paulo, Martins Fontes, 1978), ver parte II, item 1: "A crise política: fascismo e Estado de exceção", e em "As transformações atuais do Estado, a crise política e a crise do Estado" (In: Nicos Poulantzas (org.). Estado em Crise. Rio de Janeiro, Graal, 1977). Mesmo com suas limitações, consideramos esse conceito (salvo engano nosso) como o mais crítico entre as análises marxistas sobre a problemática - isto é, da elaboração do conceito de crise política em geral, especificamente das crises que dizem respeito à transformação de curto prazo das sociedades humanas. Nesses trabalhos, a crise revolucionária está subentendida, não ganhando, porém, um tratamento específico. A importância e especificidade do tratamento poulantziano das crises políticas passaram, em geral, despercebidas, uma vez que tendeu a se tomar, unilateralmente, como parâmetro as análises de Lênin sobre a crise revolucionária. Sabemos que Lênin elaborou valiosas indicações analíticas práticas sobre os diversos aspectos da crise política, principalmente sobre a crise revolucionária. 0 caráter teórico de tais indicações foi da maior importância na medida em que serviu de ponto de partida para pensar a crise revolucionária em geral e para analisar as revoluções burguesas. Entretanto, ninguém negaria a sua limitação pelo fato de tais observações teóricas estavam circunscritas à experiência revolucionária russa

94 Elementos para uma análise marxista da instabilidade política no Estado burguês 
que ela é um efeito do conjunto das contradições cujas causas fundamentais aparecem ocultas. A idéia de situação remete à noção de momento político atual (Lênin), enquanto fenômeno conjuntural, com caráter específico e singular. Já a idéia de condensação de contradições não permite reduzir ou limitar o conceito à sua característica conjuntural (concepção predominante em vários autores, inclusive autores marxistas). Bem pelo contrário, possibilita compreender a problemática tomando em conta a relação dos momentos conjuntural e estrutural na noção de condensação de contradições. A crise geral e a crise política em particular revelariam a especificidade da condensação das contradições - isto é, o caráter peculiar das contradições provocadas pela confluência desses dois momentos específicos, possuindo duas temporalidades próprias. É por isso que a análise marxista das crises políticas não se esgota na análise de conjuntura: devemos lembrar o primado da crise estrutural e a noção da hierarquia das contradições inerentes em toda formação social, como muito bem o mostrou Marx (especialmente em O Capital e em O 18 Brumário), Lênin, Gramsci (em suas análises sobre as crises econômicas e crises orgânicas), Mao Tsetung e, sobretudo, Althusser (em "Contradição e sobredeterminação") e Poulantzas. Consideramos da maior importância recorrer à noção de periodização (aplicada às esferas econômica, política e ideológica de uma formação social) na análise das crises políticas para desvendar o caráter das mesmas, tal como o fizera Marx em O 18 Brumário e retomada por Poulantzas em Poder político e classes sociais: uma periodização propriamente política aplicada às modificações das formas de regime (que diz respeito às mudanças da cena política ou às modalidades concretas de organização e representação política relativa à ação aberta ou declarada das forças sociais); e outra aplicada às transformações das formas de Estado (periodização de uma formação social, que analisa as mudanças dos estágios econômicos ou luta

de 1905 e 1917 (Cf. A falência da Segunda Internacional): Lênin não se preocupou em elaborar uma teoria definida, de forma sistemática, de crise política, pois os imperativos históricos do momento eram outros. Em relação a este último ponto, o mesmo pode-se dizer de Gramsci, Mao Tse-tung e G. Lefèbvre, que retomam as preocupações teóricas de Lênin e avançam na análise do fenômeno da crise política em geral no quadro do Estado burguês. 0 primeiro propôs os conceitos de crise orgânica e crise de hegemonia, as quais repercutem na crise de representação partidária e na organização interna do aparelho de Estado. Em Sobre a contradição Tse-tung propôs pensar as crises políticas no quadro teórico da contradição dialética, mas suas preocupações estiveram voltadas para a revolução chinesa. Tais limitações também devem nos alertar de certas posturas metafísicas presentes no autor: a idéia de que a contradição estaria em todo lugar.

Economia e sociedade no capitalismo contemporâneo

cadernos cemarx, n-03-2006 95 
econômica e seu nexo com as modificações do bloco no poder, ou seja, à relação do Estado com a hegemonia de classe e com o bloco no poder). ${ }^{10}$

Por outro lado, o nosso conceito não reduz a crise política à idéia de ruptura, menos ainda à idéia de ruptura revolucionária, embora as implique. A crise revolucionária seria uma situação que condensa um conjunto complexo de contradições que chega ao ponto de ruptura explosiva provocada pela exacerbação das lutas de classes. Numa palavra, torna-se imprescindível na análise distinguir os diversos tipos de contradições e de crises políticas, dentre as quais as mais importantes seriam: de hegemonia ou crise orgânica (crise de Estado), de organização interna do aparelho de Estado, de organização e representação partidária, crise de sucessão governamental, crise ideológica, crise de legitimidade. O caráter da condensação das crises políticas tende a refletir o caráter das contradições, o sentido da confluência dos momentos estrutural e conjuntural. A dinâmica das modificações das crises políticas, determinadas pela contradição e pela luta de classes, seria pautada por uma lógica hierárquica, conforme o movimento dialético presente da realidade concreta, duma situação concreta numa formação social.

Em relação à condensação de contradições no nível político, as crises afetam tanto as relações de classe na luta política quanto o aparelho de Estado, sendo a crise do Estado um dos seus aspectos importantes. Por seu turno, uma crise econômica não se traduz necessariamente em crise política, nem uma crise política resulta necessariamente em uma crise econômica. Entretanto, ocorre que, em circunstâncias específicas, é possível que uma crise econômica se traduza em crise política que afete profundamente o conjunto das relações sociais. Mas a especificidade dessa crise não apenas reside na sua manifestação econômica, como também no seu desdobramento em crise política, crise ideológica e crise do Estado. Este tipo particular de crise política é denominado crise de hegemonia (crise orgânica ou crise estrutural).

A crise de hegemonia é devida à incapacidade de uma classe ou fração de classe dominante impor sua direção política às demais classes ou frações que compõem o bloco no poder e ao conjunto da sociedade (formação social). Esta é uma crise profunda "que afeta o conjunto das relações sociais (crise econômica e crise política) e que se

10. A despeito das contradições e deslizes teóricos de Poulantzas, criticados por Saes em seus diversos trabalhos, em relação a um conjunto de temas e questões como, por exemplo, os conceitos de cena política, formas de Estado e formas de regime.

96 Elementos para uma análise marxista da instabilidade política no Estado burguês 
manifesta, numa conjuntura, como situação de desvendamento e de condensação das contradições inerentes à estrutura social"11. Enquanto manifestação das contradições do bloco no poder, ela tem uma repercussão notável na crise do Estado. Mais especificamente, a crise de hegemonia projeta elementos da crise no seio dos aparelhos de Estado, provocando rupturas profundas dos mesmos. Pode-se dizer que a essas rupturas responde o Estado de exceção (Estado militar etc.).

Passemos agora a precisar o conceito de instabilidade política. Ela não deve ser vista como anomalia, como um fenômeno que interrompe o funcionamento "harmonioso do sistema", ou rompe o equilíbrio de um sistema supostamente "integrado". Nem deve ser entendida como um fenômeno sempre presente, permanente, como possuindo causas transhistóricas (cultura política do país, domínio do Estado sobre a "sociedade" etc.). Tampouco deve ser vista como o "oposto" de estabilidade política - isto é, como duas situações que contêm uma relação antinômica; bem pelo contrário, trata-se de dois conceitos que se referem a um só fenômeno. No entanto, considerar o caráter dialético do fenômeno (estabilidade/instabilidade) não implica que a sua análise deva se restringir à observação do restabelecimento do equilíbrio do sistema, conforme defendem as teorias funcionalista-sistêmicas. ${ }^{12}$

Pensamos que a instabilidade política apresenta uma semelhança conceitual com o conceito de crise política. Ligada ao campo da luta de classes e à relação deste com o Estado, a instabilidade política também manifesta, através de "efeitos pertinentes", uma "situação particular de condensação das contradições". Entendida assim, a instabilidade política - as suas variações ou seus diversos tipos particulares -, embora diga respeito a uma situação-conjuntura precisa, não se reduz a uma espécie de deflagração

11. Poulantzas, “As transformações atuais do Estado", cit., p. 10.

12. Essas teorias empenham-se em buscar uma definição capaz de verificar que estabilidade seria "um estado do sistema, num determinado espaço de tempo" - isto é, ela seria "o resultado de uma certa disposição dos elementos do sistema". Assim, estabilidade política é definida como a "capacidade previsível que um sistema tem de se prolongar no tempo" ou de se "manter através das adaptações". Isso significa que tal definição, além de não ultrapassar o nível empírico, parte do suposto do restabelecimento do "equilíbrio sistêmico" de um determinado sistema político. É por isso que os autores desta linha teórica se empenham somente em descobrir o grau de estabilidade de um sistema particular. Ver "Estabilidade política". In: Norberto Bobbio et al. Dicionário de Política. Brasília, Editora UnB, 2000, p. 394-395. Outra linha teórica, nos moldes da corrente norte-americana funcionalista-sistémica, porém com predominância da corrente política institucionalista francesa, que se centra na análise da dinâmica das crises políticas, é a defendida por Michel Dobry (Sociologie des crises politiques - La dynamique des mobilizations multisectorielles, Paris, Foundation Nacional des Sciences Politiques, 1986).

Economia e sociedade no capitalismo contemporâneo

cadernos cemarx, n-03-2006 97 
momentânea ou instantânea, "mas constitui um processo efetivo, com ritmo próprio, com tempos fortes e fracos, com altos e baixos, e que pode freqüentemente se estender por um longo período". ${ }^{13}$ Isso significa que as diversas modalidades (variância do fenômeno) de instabilidade política dependem da emergência dos diversos tipos de crise política, e por outro lado, da relação da luta de classes com as estruturas do Estado, cujos limites são fixados por estas, numa conjuntura específica de uma formação social capitalista concreta. Em síntese, a variância do fenômeno depende da deflagração das crises políticas numa conjuntura concreta numa formação social e a sua invariância está determinada pelas funções essenciais do Estado burguês e da sua relação com a luta de classes.

Por outro lado, partimos do suposto teórico de que haveria uma relação entre crise política e instabilidade política, e de forma geral, uma relação entre crises econômicas que provocam instabilidade na esfera política. Acreditamos que tal relação pode apresentar-se, repetimos, de forma dialética - isto é, haveria uma reciprocidade entre os dois fenômenos, o que nos alertaria para não cairmos seja num determinismo econômico, seja num determinismo político ou ideológico. Mais especificamente - e aqui nos apoiamos nas conclusões relevantes de Saes sobre a relação entre dialética e história -, devemos tomar em conta o desenvolvimento da teoria marxista da história que implica a formulação de leis distintas para ordens distintas do processo social: "a lei da interconexão sem determinação - ou a implicação recíproca - entre estruturas de um modo de produção é aplicável na análise dos processos sociais de curto prazo, ou seja, dos processos de funcionamento reprodutivo das sociedades humanas. E a lei do caráter em última instância determinante do 'fator econômico' (mais exatamente, do desenvolvimento das forças produtivas) é aplicável na análise dos processos sociais de longo prazo, que implicam a transformação qualitativa das sociedades humanas: são os processos de transição de um modo de produção a outro"14. Nessa linha de raciocínio, Saes - apoiado em Bettelheim, para quem, nas sociedades de classe, "opera um processo de negação-conservação" -, argumenta que esta conclusão estaria mais perto da expressão utilizada por Marx nas suas análises da reprodução do capital, particularmente na "Introdução à critica da economia política", de 1857. Haveria, assim, nos processos de funcionamento reprodutivos sociais de curto prazo "um mecanismo

13. Poulantzas, "As transformações atuais do Estado", cit., p. 12.

14. Saes, “Marxismo e história”. Crítica Marxista, São Paulo, Brasiliense, nº 1, 1994, p. 56-57; grifo nosso.

98 Elementos para uma análise marxista da instabilidade política no Estado burguês 
de negação-conservação que opera no processo de reprodução social"15. As nossas observações teóricas sobre o caráter dialético da estabilidade/instabilidade política devem ser circunscritas a esse aspecto teórico crucial $^{16}$.

Assim, a análise da relação entre crise e instabilidade política, bem como a relação instabilidade/estabilidade política deve tomar em conta esses elementos teóricos mencionados.

\section{CONCLUSÃo}

As crises gerais, e as crises políticas em particular, estão estreitamente articuladas com o fenômeno da instabilidade política; ou então, podem ser causadoras potenciais de instabilidade no nível político. Daí a nossa proposição geral (já enunciada mais acima): se o Estado burguês é um Estado eivado de crises e contradições (política, econômica, ideológica), se é portador de elementos genéricos de crise que "estão presentes e permanentemente em ação na reprodução das relações capitalistas" 17 , ele também se configura como um Estado potencialmente instável. Mais especificamente, ele oscila entre estabilidade e instabilidade política de acordo com a luta de classes e a deflagração das contradições e crises numa determinada formação social. Nesse sentido, longe de considerar o Estado burguês como um Estado que mantém uma instabilidade política endêmica, ele tem a capacidade - limitada, portanto, pela luta de classes - de absorver suas crises e de adaptar-se diante das novas exigências determinadas pela fase pela qual atravessa, entrando, assim, em novas crises e contradições, passando a manifestar novas modalidades de instabilidade política.

15. Idem, ibidem, p. 59; grifo nosso.

16. Se a nossa leitura sobre esse aspecto teórico não estiver errada (isto é, uma redução do conceito negaçãoconservação pelo conceito marxiano, que a seguir se especifica), um mecanismo semelhante foi detectado por Marx (nas Formen e em O [apital): o de dissolução-conservação, amplamente utilizado nas suas análises sobre os modos de produção e das formações sociais. Esclareça-se: na linha de raciocínio de Saes, apenas estamos levantando a hipótese indicativa da possibilidade de que o conceito de negação-conservação de Betthelleim tenha se baseado nas observações teóricas, de caráter prático, formuladas por Marx, sobre 0 conceito dissolução-conservação. Esta observação, a nosso ver, de maneira nenhuma altera o conteúdo e potencialidade da tese defendida por Saes sobre a distinção fundamental dos dois processos reprodutivos das sociedades humanas no seu artigo mencionado.

17. Poulantzas, “As transformações atuais do Estado", cit., p. 6.

Economia e sociedade no capitalismo contemporâneo

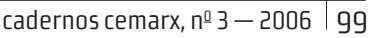

